
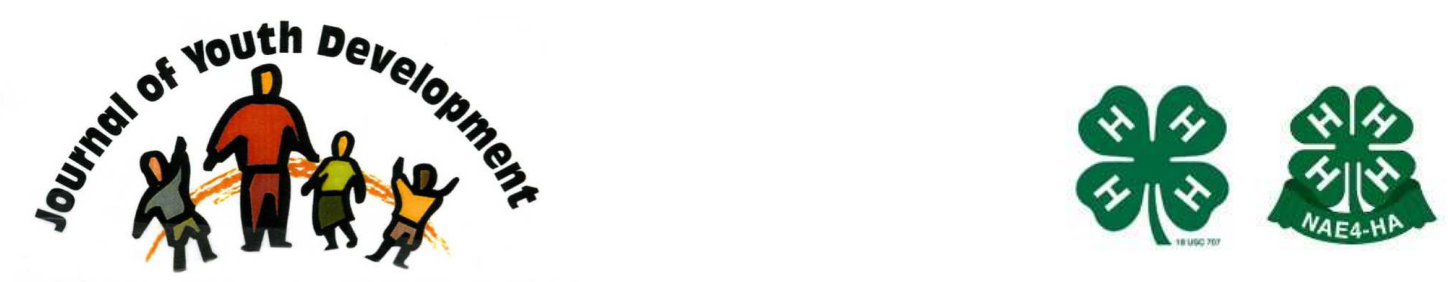

Bridging Research \& Practice

\title{
Positive Youth Development in the Midst of Coping with Parental Cancer: Implications for Youth Development Research and Practice
}

\author{
Kerri L. Ashurst \\ University of Kentucky \\ Lexington, $\mathrm{KY}$ \\ kgoodman@email.uky.edu \\ Jason D. Hans \\ University of Kentucky \\ Lexington, $\mathrm{KY}$ \\ jhans@uky.edu \\ Donna R. Smith \\ University of Kentucky \\ Lexington, $\mathrm{KY}$ \\ donnarsmith@uky.edu \\ Kenneth R. Jones \\ University of Kentucky \\ Lexington, $\mathrm{KY}$ \\ krjone3@email.uky.edu
}




\title{
JOURNAL OF YOUTH DEVELOPMENT \\ bridging research and practice

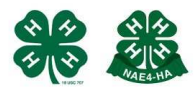

Volume 5, Number 3, Fall 2010

Article 100503FA004

\section{Positive Youth Development in the Midst of Coping with Parental Cancer: Implications for Youth Development Research and Practice}

\author{
Kerri L. Ashurst, Jason D. Hans, Donna R. Smith and Kenneth R. Jones \\ University of Kentucky
}

\begin{abstract}
Four implications for youth development research and practice resulted from a qualitative study on psychosocial developmental experiences of late adolescents coping with parental cancer during late adolescence. The study employed a developmental systems framework and grounded theory methods. Results suggest three primary psychosocial developmental influences, including multilevel influences (individual, familial, and extrafamilial risk and protective factors), coping strategies to maintain control, and responses to uncertainty and anticipatory grief. The particular combination of risk and protective factors present in participants' lives resulted in positive outcomes; resilience was the central unifying concept that characterized the primary psychosocial developmental outcomes of each participant. This finding illuminates the need to expand our focus in youth development research and practice to include positive developmental outcomes that can result from coping with life crises during adolescence.
\end{abstract}

\section{Introduction}

Death and dying are uncomfortable topics of discussion in our society, especially with regard to non-normative experiences such as the loss of a child or the loss of a sibling or parent during childhood or adolescence. Despite the accompanying discomforts, cancer diagnoses commonly prompt families to confront death and dying because there is a widely held belief that a cancer diagnosis is essentially a death sentence (Hersh, 1997).

The perceived inevitability of death associated with cancer distinguishes the coping experiences of these families from those coping with other types of chronic or life-threatening illnesses. The anticipation of an impending death in the family may be especially challenging for adolescents, 
who do not have the luxury of putting physical, cognitive, and emotional developmental tasks on hold while engaging in grief work (Balk, 1998) or while living with constant uncertainties in their family lives.

Loss, and presumably anticipated loss, of a parent places adolescents at developmental risk (Kiser, Ostoja, \& Pruitt, 1998). However, little is currently understood about the contextual factors that may moderate developmental outcomes among adolescents coping with parental cancer. Research is needed that examines the positive developmental outcomes adolescents may experience stemming from a parent's diagnosis, illness, or death due to cancer.

This article draws implications for youth development from a qualitative study that inductively examined the psychosocial developmental experiences of adolescents coping with parental cancer. The study took an inductive approach by allowing the findings to emerge from the voices of the youth who were coping with parental cancer rather than testing preconceived notions or hypotheses about their experiences. The findings from this study are instructive for youth development researchers and practitioners who want to better understand adolescents within various contexts as they cope with illness, death, and other major life crises. The findings identify "windows of opportunity" for where, how, and when youth development researchers and practitioners can be most helpful.

This article reviews three major areas:

(1) background on the field of youth development and related theoretical development and how this history pertains to the topic of adolescent development at the interface of coping with parental cancer;

(2) a short summary of findings from the qualitative study (Ashurst, Hans, \& Smith, in press); and

(3) a discussion of implications and recommendations for the future of youth development research on adolescent development in the midst of coping with a major life crisis.

\section{Background}

Throughout most of the 20th century, adolescence researchers viewed youth development through a negative lens by focusing on shortcomings and the "storm and stress" of adolescence (Hall, 1904; Lerner, Lerner, Phelps, \& Colleagues, 2008). This perspective has been especially prevalent in the study of grief and loss among adolescents. Experiences of parental death or dying during adolescence have been viewed as an extremely negative experience that disrupts adolescents' normative development (Balk, 1996).

Bereavement experiences in adolescence can lead to debilitating consequences when grief interferes with normative developmental task in adolescence (Balk, 1998). However, findings have been mixed concerning the outcomes of adolescents who have experienced parental death and dying. Some studies have detected considerable adjustment problems (i.e., Kranzler, Shaffer, Wasserman, \& Davies, 1989; Robinson, 1998; Siegel, Mesagno, Karus, Christ, Banks, et al., 1992; Thompson, Kaslow, Kingree, King, Bryant, et al., 1998). Other studies have found positive developmental effects, such as bereaved adolescents emerging more emotionally and interpersonally mature than unaffected peers (Balk, 1996) or anticipatory grief aiding in recovery after a death (Parkes, 1975; Peterson \& Rafuls, 1998). The benefits of anticipatory grief, a common experience with parental cancer, are themselves unclear because some studies 
have found no differences between adolescents who had ample time to anticipate a parent's death and those who did not (Moss \& Moss, 1996; Peterson \& Rafuls, 1998).

The generally negative lens through which adolescence was examined for most of the past century changed dramatically over the past two decades. The emphasis of youth development research and interventions has shifted away from the deficit approach that focused on prevention of problems and problem behavior to an emphasis on positive youth development (Jones, 2005). Despite the developmental challenges adolescents may face, evidence reveals that the majority of adolescents experience these years as times of relative calm and stability (Balk, 1995). This new knowledge has led to the Positive Youth Development (PYD) framework, which views youth as resources to be developed rather than as problems to be managed (Damon, 2004; Lerner, 2005) and emphasizes the need for promotion of asset building and examining the role of resiliency in adolescents' lives (Jones, 2005).

This focus on resiliency and plasticity underscores the role that youth can play in fostering their own development (Jones \& Perkins, 2006). Furthermore, the ecological context - homes, schools, and communities - plays an important role in shaping developmental experiences and outcomes (Bronfenbrenner, 1979; Lerner, 2006). This new understanding and awareness that adolescents' trajectories are not fixed has led researchers to develop increasingly sophisticated approaches for overcoming the limitations of individual theoretical perspectives. The human development models that have emerged eschew the reduction of individual and social behavior to fixed genetic influences and instead stress the relative plasticity of human development (Lerner, Almerigi, Theokas, \& Lerner, 2005).

The PYD framework has arisen because of interest among developmental scientists in using developmental systems, or dynamic models for understanding the plasticity of human development and relations between individuals and their real-world ecological settings (Lerner et al., 2008). The use of developmental systems is becoming increasingly prominent in literature on grief and illness (Lerner et al., 2005), where it posits that prolonged stages of illness, constant uncertainty, and anticipatory grief carry the potential to disrupt emotional detachment from parents, relationships with peers, or academic performance (Siegel, Karus, \& Raveis, 1996).

However, this approach also suggests the potential for positive, healthy development by aligning the strengths of adolescents with the resources for positive development present in their diverse ecologies (Lerner et al., 2005). Thus, the individual and systemic coping and adaptation process associated with illness or death of a parent during adolescence can elicit both risk and protective factors, which may explain the contradictory findings of previous research on adolescent outcomes following parental death and dying experiences. An integrative developmental systems perspective framed the qualitative study summarized below with a view of adolescents as developing individuals who are simultaneously part of an interdependent family system and a larger, interdependent ecological context.

\section{Summary of Qualitative Grounded Theory Study}

The study from which implications for this article were drawn addressed gaps in the grief literature by focusing on four primary areas:

- $\quad$ targeting adolescents rather than younger children (Marwit \& Carusa, 1998); 
- targeting adolescents who had not yet experienced the loss of an ill parent rather than only adolescents who had already experienced the loss of a parent (Morin \& Welsh, 1996);

- attending to influences on outcome (Dowdney, 2000); and

- separating adolescents by developmental stage (Marwit \& Carusa, 1998).

Furthermore, this study addressed gaps on multilevel influences on adolescents' perceptions or experiences of death (Morin \& Welsh, 1996), influences or experiences specific to developmental stage (Marwit \& Carusa, 1998), influential factors on individual concepts of death (Morin \& Welsh, 1996), and protective factors that may influence outcome (Dowdney, 2000).

The sample consisted of five males and three females in late adolescence (ages 18-21) who had a parent diagnosed with cancer. The procedures for data collection and analysis were modeled after grounded theory principles originally put forth by Glaser and Strauss (1967) and by Strauss and Corbin (1990; 1994; 1998). Data were collected through in-depth, semi-structured qualitative interviews guided by 13 open-ended questions about coping with parental cancer during late adolescence which were designed to gain a better understanding of psychosocial developmental experiences and impacts.

Inductive analysis using the constant comparative method (Glaser \& Strauss, 1967) was utilized, whereby each new interview was compared to categories that had emerged from previous interviews. Systematic notes were kept for each participant throughout the research process to record the conceptual development of emergent themes (Glaser \& Strauss, 1967). Once an overall familiarity with the data was obtained, Nvivo ${ }^{\mathrm{TM}}$ qualitative data management software was used to facilitate open and axial coding. Ultimately, nine categories containing 30 codes were generated. Selective coding was then used to validate the relationships between the codes and categories as well as the interrelationships between categories.

The study focused on two research questions:

- What are the most important psychosocial developmental influences identified by late adolescents who are coping with parental cancer?

- What are the particular psychosocial developmental experiences or impacts that result from coping with parental cancer during late adolescence?

Ashurst, Hans, \& Smith (in press) provides a fuller description of the methodology and results. However, a short summary of the results are provided below as a backdrop for the youth development research and practice implications that follow. For the first research question, three primary psychosocial developmental influences emerged from participants' experiences (see Table 1). 
Table 1

Research Question 1: Psychosocial Developmental Influences

\begin{tabular}{|l|l|l|}
\hline Influence & Subcategories & Relationship to Developmental Task \\
\hline $\begin{array}{l}\text { Multilevel } \\
\text { Influences in Daily } \\
\text { Lives }\end{array}$ & $\begin{array}{l}\text { Individual: perceived role in family; } \\
\text { personal theories on the experience } \\
\text { of parental cancer }\end{array}$ & Autonomy and identity \\
\cline { 2 - 3 } & $\begin{array}{l}\text { Familial: attachments, } \\
\text { communication, family dynamics, } \\
\text { prior losses, family roles }\end{array}$ & Intimacy, autonomy, identity \\
\cline { 2 - 3 } & $\begin{array}{l}\text { Extra familial: ignorance, support, } \\
\text { understanding }\end{array}$ & Intimacy \\
\hline $\begin{array}{l}\text { Coping Strategies to } \\
\text { Maintain Control }\end{array}$ & $\begin{array}{l}\text { Appraisal: denial, journaling, } \\
\text { negative thinking, theorizing }\end{array}$ & Identity \\
\cline { 2 - 3 } & $\begin{array}{l}\text { Problem-focused: multiple stresses, } \\
\text { knowledge seeking, priority changes }\end{array}$ & $\begin{array}{l}\text { Achievement, autonomy, identity, } \\
\text { intimacy, sexuality }\end{array}$ \\
\cline { 2 - 3 } & $\begin{array}{l}\text { Emotion-focused: escape, } \\
\text { fantasizing, guilt, humor }\end{array}$ & $\begin{array}{l}\text { Achievement, identity, intimacy, } \\
\text { sexuality }\end{array}$ \\
\hline Responding to & $\begin{array}{l}\text { Triggers: changes in the ill parent, } \\
\text { Uncertainty }\end{array}$ & Identity \\
\cline { 2 - 3 } & $\begin{array}{l}\text { Concerness, suddenness } \\
\text { self, future losses, post-death } \\
\text { changes }\end{array}$ & $\begin{array}{l}\text { Autonomy, identity, intimacy, } \\
\text { sexuality }\end{array}$ \\
\cline { 2 - 3 } & $\begin{array}{l}\text { Meaning making: advice to others, } \\
\text { closure, faith, legacy }\end{array}$ & Achievement, autonomy, identity \\
\hline
\end{tabular}

The first influence was multilevel influences present in their daily lives. These included individual, familial, and extra familial levels of risk and protective factors. The second influence was coping strategies to maintain control. These were a route for accomplishing or hindering the psychosocial tasks of late adolescence in the midst of their family crises. The third influence was responding to uncertainty and anticipatory grief. Uncertainty was an important factor in understanding participants' responses to illness and dying because the chronic stress from uncertainty left them to feel like they had no control.

For the second research question, the central unifying concept of resilience was the primary psychosocial developmental experience and impact that resulted from coping with parental cancer during late adolescence. Participants believed they had experienced a "fork in the road" where they consciously decided which way they were going to go. All participants chose the positive route, which revealed a form of resilience in action. This conscious choice to take a resilient path seemed to impact all aspects of their psychosocial experience.

The resulting maturity they gained then fed back into their individual, familial, and extra familial experiences, which enhanced their coping strategies and responses to uncertainty and anticipatory grief, and facilitated further psychosocial development. There were positive outcomes mentioned for each of the five psychosocial developmental tasks (Hill, 1980): achievement, autonomy, identity, sexuality, and intimacy (see Table 2). 
Table 2

Positive Outcomes on Psychosocial Development

\begin{tabular}{|l|l|}
\hline Psychosocial Developmental Task & Positive Outcomes \\
\hline Achievement & $\begin{array}{l}\text { All participants shared that the experience of parental } \\
\text { cancer taught them to be competent and resulted in an } \\
\text { increase in their achievement orientation. }\end{array}$ \\
\hline Autonomy & $\begin{array}{l}\text { All participants agreed they had become more independent } \\
\text { as a result of their experiences. }\end{array}$ \\
\hline Identity & $\begin{array}{l}\text { All participants saw how their identities had developed and } \\
\text { changed over the course of their parent's illness and could } \\
\text { articulate these changes. }\end{array}$ \\
\hline Intimacy & $\begin{array}{l}\text { All participants developed a greater level of intimacy with } \\
\text { parents, siblings, friends, other adults, or some } \\
\text { combination of these. Greater intimacy led to increased } \\
\text { ability to express themselves and greater empathy and } \\
\text { caring about others. }\end{array}$ \\
\hline Sexuality & $\begin{array}{l}\text { Two participants articulated awareness of connections } \\
\text { between their experiences with parental cancer and their } \\
\text { sexual development. }\end{array}$ \\
\hline
\end{tabular}

This study was not designed to gain a representative understanding of experiences among adolescents whose parents have been diagnosed with cancer. Although these findings are instructive with regard to positive youth development in the context of family crises, they should not be considered representative of all coping experiences and outcomes. This was a small sample who self-selected themselves for participation, which likely biased the findings toward resilient or positive outcomes.

This study also focused on a specific developmental stage, and experiences may differ according to developmental stage. Despite these limitations, the findings provide a rich description of the participants' experiences couched in a developmental and systemic context, which may be useful for researchers and practitioners working with youth and families who are coping with cancer or other major life crises.

\section{Implications for Youth Development Research and Practice}

Resilience was used to describe the participants' experiences rather than restoration because the positive development occurred prior to a parent's death. Nevertheless, the central role of resilience in these participants' experiences supports the notion put forth by Stroebe and Schut (1999) and Balk (1998) that more attention needs to be directed toward restoration, a positive aspect of development that can occur after (and perhaps during) parental loss.

The psychosocial developmental influences summarized in Table 1, and especially the overall finding of resilience as the primary psychosocial developmental impact, may provide insight into the mixed findings of prior research on adolescent outcomes following parental death. As the late adolescents in this study coped with parental cancer, they drew upon all of the psychosocial developmental influences to integrate the experience into their lives. These influences included risk factors associated with their individual and family backgrounds and larger environmental contexts, which can create vulnerability to distress or negative 
consequences (Thompson et al., 1998). However, protective factors were also present and seemed to moderate participant's vulnerability to negative consequences.

The particular combination of risk and protective factors in this study resulted in positive outcomes for the participants. The discovery of resilience as a primary impact underscores research findings by Balk (1996) that most adolescents emerge from their bereavement more emotionally and interpersonally mature than unaffected peers their own age. It also provides support for Balk's (1991) finding that adolescents do experience positive outcomes from grief experiences, as these participants were able to identify positive outcomes for both their present and future psychosocial development.

Over the course of this study, it became apparent that outcomes were dependent on the presence and salience of various risk and protective factors. Positive, neutral, and negative outcomes are all plausible outcomes for adolescents coping with parental cancer, depending on the characteristics of the psychosocial developmental influences that are present.

This finding lends support to the developmental systems model, which posits that an experience like coping with parental cancer can disrupt psychosocial tasks (Siegel, Karus, \& Raveis, 1996) but also suggests that the potential for healthy developmental outcomes exists, regardless of diverse ecologies (Lerner, Almerigi, Theokas, \& Lerner, 2005). This notion was the central finding from this study, where risk and protective factors were both discovered, yet resilience was the primary outcome from the unique influences, coping skills, and uncertainties in these participants' lives. As a result of this central study finding, four primary implications are offered below that are directly related to youth development research and practice.

\section{Research on Risk and Protective Factors during a Life Crisis}

The experiences of participants in this study highlight the lack of knowledge in the current literature about risk and protective factors. The concepts presented in this study contained a combination of risk and protective factors, but each participant seemed to have enough protective factors present in their lives to take a resilient path. Researchers need to continue gathering information from people at the time they are going through a major life crisis as this study did to move research forward about vulnerability to or protection from negative outcomes. By focusing exclusively on retrospective accounts, it is difficult to disentangle the effects of the experience of coping with parental cancer during adolescence from the effects of subsequent life circumstances. Furthermore, studies that have focused only on retrospective accounts leave questions about the generalizability of findings to adolescents who are currently going through the experience and what needs to be done to bolster protective factors and minimize risk factors. Gathering information during the time of a major life crisis can ultimately result in more effective interventions in working directly with these adolescents and their families as they are actively coping with parental cancer.

\section{Examination of Positive Outcomes}

There is a lack of published research on positive outcomes that may result from the experience of coping with parental cancer during the different stages of adolescence. This study expands our understanding of the experiences and needs of late adolescents coping with parental cancer by identifying a multitude of factors associated with positive outcomes and resilience. Resilience-based and asset-based models should be integrated into examinations of young people who are coping with parental illness or death. An important question not answered in 
this study that should be examined in future studies is the relative contribution each protective factor makes toward resilient outcomes.

\section{Minimizing Risk Factors and Maximizing Protective Factors}

Practitioners need to help late adolescents identify and accentuate the protective factors that are already present in their lives, and assist them in developing protective factors they are lacking. Some of the protective factors in this study that had strong connections with the finding of resilience included attachments and closeness with family members, increases in communication, perceiving the non-ill parent as helpful, support or understanding from others, reestablishing routines or normalcy, perseverance, self-reliance, peace of mind, faith, helping others, priority changes, opportunities for escape, and humor.

Practitioners also need to help late adolescents become aware of risk factors that are present in their lives and plan strategies to reduce the influence of these risks. Some risk factors that served as barriers to resilience for these participants included avoidance of family communication, addiction, cutoff relationships, secrets, emotional suppression, triangles, perceiving the non-ill parent as unhelpful, prior losses, ignorance of others, denial, pessimism, juggling multiple stresses, use of drugs or sex to escape, guilt, feeling helpless, suddenness, fears for self, concerns about future losses, and barriers to closure. Practitioners can also reframe risk factors as opportunities for growth or skill development that could become protective factors if they motivate a late adolescent to find ways to gain strength out of adversity.

\section{Continuing and Expanding the Use of Integrated Theoretical Perspectives}

Integrated theoretical perspectives are appearing with greater frequency as researchers attempt to overcome the limitations of individual theories. Contemporary integrative theories like developmental systems eschew the reduction of individual and social behavior to fixed genetic influences and stress the relative plasticity of human development (Lerner et al., 2005). Furthermore, developmental systems models argue that the potential for systematic change in behavior exists as a consequence of mutually influential relationships between the developing person and his or her biology, psychological characteristics, family, community, culture, physical and designed ecology, and historical niche (Lerner et al., 2005).

Individual theories of human behavior are incapable of capturing the complexity of many issues, including coping with parental cancer during late adolescence. The resilience that characterized participants in this study provides support for the developmental systems notion that there is potential for positive, healthy development, regardless of diverse ecologies (Lerner et al., 2005). Further grounded theory development utilizing developmental systems models with this population and other populations who are coping with parental illness or death will aid in further refinement of the model that emerged from this study.

As patterns emerge and more adequate integrative models are developed, the theories that emerge can drive effective practice for working with many age groups and types of crises. Eventually, theory may identify specific protective factors that are most closely associated with positive outcomes and specific risk factors that are most closely associated with negative outcomes. In addition, the finding of resilience as a central unifying concept in this study supports the need for development and refinement of resilience and asset-based theoretical models. Boss' (2006) therapeutic approach to ambiguous loss is noteworthy in this regard. 


\section{Conclusion}

The potential for change is a core strength of all youth that can be built upon, which is a cause for optimism because it means we can influence the life paths of children in a positive direction (Lerner et al., 2008). In other words, adolescence is a time of numerous changes, more so than at any other point in the life span. However, this presents a unique opportunity to intervene to bolster protective factors, help adolescents to visualize a positive future for themselves, and find ways to actively reach toward positive outcomes. Although parental cancer and death certainly have the potential to cause long-term negative consequences for adolescents, the participants in this study demonstrated that positive outcomes are possible when adequate protective factors are present. Examples of positive outcomes experienced by these participants include increased maturity, increased life skills, competencies gained for coping with future problems and crises, improved self-esteem and confidence, and improved physical and mental health.

Future research should further examine the factors that produce these positive outcomes (Balk, 1998; Stroebe \& Schut, 1999; Tyson-Rawson, 1996). As our evidence-based knowledge and theoretical models identify pathways that lead to healthy outcomes following traumatic life experiences, practitioners should strive not only to minimize negative outcomes, but focus on to maximizing positive outcomes. In the end, researchers, practitioners, and theory builders all can play a role in assisting people in gaining strength through adversity.

"Don't let it win. Even if, by chance, that it does take a parent's life, still, don't let it win. You always have the power to get the upper hand over it, at least mentally."

- Study participant

\section{References}

Ashurst, K.L., Hans, J.D., \& Smith, D.R. (in press). The resilience factor: What Extension can learn from adolescents coping with parental cancer. The Journal of Extension.

Balk, D.E. (1991). Death and adolescent bereavement: Current research and future directions. Journal of Adolescent Research, 6, 7-27.

Balk, D.E. (1995). Adolescent development: Early through late adolescence. Pacific Grove, CA: Brooks/Cole.

Balk, D.E. (1996). Models for understanding adolescent coping with bereavement. Death Studies, 20, 367-387.

Balk, D.E. (1998). Psychological development during four years of bereavement: A longitudinal case study. Death Studies, 22, 23-36.

Boss, P. (2006). Loss, trauma, and resilience: Therapeutic work with ambiguous loss. New York: W.W. Norton and Company.

Bronfenbrenner, U. (1979). The ecology of human development. Cambridge, MA: Harvard University Press. 
Damon, W. (2004). What is positive youth development? Annuals of the American Academy of Political and Social Science, 591, 13-24.

Dowdney, L. (2000). Childhood bereavement following parental death. Journal of Child Psychology and Psychiatry, 41, 819-830.

Glaser, B., \& Strauss, A.L. (1967). The discovery of grounded theory: Strategies for qualitative research. Chicago: Aldine.

Hall, G.S. (1904). Adolescence: Its psychology and its relations to psychology, anthropology, sociology, sex, crime, religion, and education. New York: Appleton.

Hersh, S.P. (1997). Death from the cancers. In K.J. Doka (Ed.), Living with grief: When illness is prolonged. Washington, DC: Hospice Foundation of America.

Hill, J.P. (1980). Understanding early adolescence: A framework. Chapel Hill, NC: University of North Carolina Center for Early Adolescence.

Jones, K.R. (2005). Positive youth development. University of Kentucky Cooperative Extension Service (4MO-0100). Retrieved on August 22, 2008, from http://www.uky.edu/Ag/CLD/YD/Pubs/PosYthDev.pdf

Jones, K.R., \& Perkins, D.F. (2006). Youth and adult perceptions of their relationships within community-based youth programs. Youth \& Society, 38, 90-109.

Kiser, L.J., Ostoja, E., \& Pruitt, D.B. (1998). Dealing with stress and trauma in families. Stress in Children, 7, 87-103.

Kranzler, E., Shaffer, D., Wasserman, G., \& Davies, M. (1989). Early childhood bereavement. Journal of the American Academy of Child and Adolescent Psychiatry, 29, 513-520.

Lerner, R.M. (2005, September). Promoting positive youth development: Theoretical and empirical bases. White paper prepared for the Workshop on the Science of Adolescent Health and Development, National Research Council/Institute of Medicine. Washington, CD: National Academy of Science.

Lerner, R.M. (2006). Developmental science, developmental systems, and contemporary theories of human development. In R.M. Lerner (Ed.), Theoretical models of human development. Volume 1 of Handbook of Child Psychology (6th ed., pp. 1-17). Editors-in-chief: W. Damon \& R.M. Lerner. Hoboken, NJ: Wiley.

Lerner, R.M., Almerigi, J.B., Theokas, C., \& Lerner, J.V. (2005). Positive youth development: A view of the issues. The Journal of Early Adolescence, 25, 10-16.

Lerner, R.M., Lerner, J.V., Phelps, E., \& Colleagues (2008). The positive development of youth. Institute for Applied Research, Tufts University. Retrieved on August 22, 2008, from http://ase.tufts.edu/iaryd/documents/4hstudyannualreport2008.pdf 
Marwit, S.J., \& Carusa, S.S. (1998). Communicated support following loss: Examining the experiences of parental death and parental divorce in adolescence. Death Studies, 22, 237-256.

Morin, S.M., \& Welsh, L.A. (1996). Adolescents' perceptions and experiences of death and grieving. Adolescence, 31, 585-596.

Moss, M.S., \& Moss, S.Z. (1996). Anticipating the death of an elderly parent. In J. D. Morgan (Ed.), Ethical issues in the care of the dying and bereaved aged (pp. 111-130). Amityville, NY: Baywood.

Parkes, C.M. (1975). Bereavement: Studies of grief in adult life. Harmondsworth: Penguin.

Peterson, S., \& Rafuls, S.E. (1998). Receiving the scepter: The generational transitions and impact of parent death on adults. Death Studies, 22, 493-524.

Robinson, F. (1998, January/February). Children: The forgotten mourners. Healthplan, 69-72.

Siegel, K., Karus, D., \& Raveis, V. (1996). Adjustment of children facing the death of a parent due to cancer. Journal of the American Academy of Child and Adolescent Psychiatry, 35, 442456.

Siegel, K., Mesagno, F.P., Karus, D., Christ, G., Banks, K., \& Moynihan, R. (1992). Psychosocial adjustment of children with a terminally ill parent. Journal of the American Academy of Child and Adolescent Psychiatry, 31, 327-333.

Strauss, A., \& Corbin, J. (1990). Basics of qualitative research: Grounded theory procedures and techniques. Newbury Park, CA: Sage Publications.

Strauss, A., \& Corbin, J. (1994). Grounded theory methodology. In N. K. Denzin \& Y. S. Lincoln (Eds.), Handbook of qualitative research (pp. 273-285). Thousand Oaks, CA: Sage Publications.

Strauss, A., \& Corbin, J. (1998). Basics of qualitative research: Techniques and procedures for developing grounded theory. Thousand Oaks, CA: Sage Publications.

Stroebe, M., \& Schut, H. (1999). The dual process model of coping with bereavement: Rationale and description. Death Studies, 23, 197-224.

Thompson, M.P., Kaslow, N.J., Kingree, J.B., King, M., Bryant, L., \& Rey, M. (1998). Psychological symptomatology following parental death in a predominantly minority sample of children and adolescents. Journal of Clinical Child Psychology, 27, 434-441.

Tyson-Rawson, K. (1996). Adolescent responses to the death of a parent. In C. A. Corr \& D. E. Balk (Eds. ), Handbook of adolescent death and bereavement (pp. 155-172). New York: Springer.

(C) Copyright of Journal of Youth Development $\sim$ Bridging Research and Practice. Content may not be copied or emailed to multiple sites or posted to a listserv without copyright holder's express written permission. However, users may print, download or email articles for individual use. 